\title{
Agglutinin response to bacterial infection in acute exacerbations of chronic bronchitis
}

\author{
A. C. NICHOLLS, ${ }^{1}$ P. E. PEASE, AND I. D. GREEN \\ From the Departments of Bacteriology and Medicine, University of Birmingham, Birmingham
}

SYNOPSIS Agglutinin titres to Haemophilus influenzae, Streptococcus pneumoniae, Klebsiella pneumoniae, Staphylococcus aureus, Pseudomonas aeruginosa, Escherichia coli, and Proteus vulgaris in the serum of patients with acute exacerbations of chronic bronchitis, patients producing mucoid sputum, and healthy controls were determined. Serological evidence of infection with $H$. influenzae was found in 38 of 57 patients with acute exacerbations, and Str. pneumoniae infection in 10 of the 57 patients, but was generally absent from healthy control subjects and from patients producing mucoid sputum. No serological evidence of infection with other organisms named above was found to be associated with exacerbations of chronic bronchitis. Ten patients with acute exacerbations were without serological evidence of infection by any of the bacteria tested.

Antibody response during chronic bronchitis was studied for the purpose of guidance in antibiotic therapy, since isolations of suspected microorganisms do not produce rapid or reliable information. The problem has been investigated by several workers, and, despite the complex antigenic structure of Haemophilus influenzae, most of the earlier workers agreed that bronchitic patients had specific antibodies to this bacterium in their serum, whereas control subjects had not (Faunce, 1958; Murdoch, Leckie, Downie, Swain, and Gould, 1959; Glynn, 1959). Wilson, Dunn, and Blair (1924), studying agglutinins to $H$. influenzae in the sera of patients suffering from influenza and other respiratory diseases, found that 208 of 220 control sera gave negative results while infected patients had titres above $1 / 80$. These titres were seen to subside rapidly in convalescence. May (1965) found that agglutinins at high titre were commonest in patients with purulent sputum and rare in normal subjects. Burns and May (1968) found precipitins to Streptococcus pneumoniae. May (1965) found inconsistencies in the occurrence of agglutinins and precipitins to $H$. influenzae, whereas Jenne, MacDonald, Lapinski, Bratberg, and Hall (1970) found that precipitin and passive haemagglutination titres reflected acute infections and exacerbations although

'Present address: Midhurst Medical Research Institute, Midhurst, Sussex, GU29 OBL.

Received for publication 19 November 1974. persisting antibodies were occasionally without apparent explanation. Several investigators have failed to demonstrate a change in titre of antibodies to $H$. influenzae during acute exacerbations of chronic bronchitis (Glynn, 1959; Morgan and Wood, 1965; Kohn, 1965; Ross, McMichael, Eadie, Lees, Murray, and Pinkerton, 1966). In this study the agglutinin titres to $H$. influenzae, Str. pneumoniae, Klebsiella pneumoniae, Staphylococcus aureus, Pseudomonas aeruginosa, Escherichia coli, and Proteus vulgaris were assessed in chronic bronchitic patients with both mucopurulent and mucoid sputum, and in healthy controls.

\section{Materials and Methods}

\section{SUBJECTS}

The subjects under investigations were classified in three groups: 57 patients in exacerbation of chronic bronchitis with purulent sputum; 22 bronchitics with mucoid sputum; 15 healthy controls.

\section{CULTURAL METHODS}

Cultures were made on nutrient agar (Oxoid), horse-blood agar, and Fildes agar, prepared according to Cruickshank (1968), but with horse blood in place of sheep.

Sputum was digested with pancreatin buffer, by the method of Rawlins (1953), before plating, and cultures were incubated at $37^{\circ} \mathrm{C}$, both aerobically and in an atmosphere with $10 \%$ added carbon 279 
dioxide. From healthy controls postnasal swabs were taken for culture.

\section{SEROLOGY}

Sera were stored at $-20^{\circ} \mathrm{C}$ without preservative. The antigens, detailed in table I, were grown in broth culture at $37^{\circ} \mathrm{C}$ for 24 hours. Those from $H$. influenzae were prepared in accordance with the technique of May (1965). After incubation, sterility checks were made on all broth cultures by plating out a $0.1 \mathrm{ml}$ sample; contaminated broths were discarded. After withdrawal of the test sample, phenol was added to the broth culture to give a final concentration of $1 \%$, and the culture was allowed to stand overnight. Antigen was collected by centrifuging the broth at $6500 \mathrm{~g}$ for 40 minutes and discarding the supernatant. The deposits were collected and washed five times in $0.5 \%$ phenol saline. The final suspension in $0.5 \%$ phenol was stored at $4^{\circ} \mathrm{C}$.

Before using the antigen in routine testing, a correlation between the number of organisms per $\mathrm{ml}$ and the opacity of Brown's tube no. 3 (Burrough's Wellcome) was derived for each antigen by a viable count technique. The optimal test concentration of each antigen was assessed by titrating each antigen against a reference rabbit serum. Each antigen was tested at five different concentrations $\left(5 \times 10^{5}\right.$, $7.5 \times 10^{5}, 8 \times 10^{5}, 1 \times 10^{6}$, and $2.5 \times 10^{6}$ organisms per $\mathrm{ml}$ ) and the concentration selected for routine tests was that which represented the highest dilution of antigen suspension which gave agglutination in the presence of the highest dilution of antiserum. A known negative serum (anti-Bacillus subtilis serum) was employed in all cases as a control check for non-specific agglutination.
Agglutinin titres were assessed by a modification of the Widal test described by Cruickshank (1968) using disposable haemagglutination trays in place of Dreyer tubes.

Serum and sputum samples produced by this group were taken from each subject on days 1, 3, 7, 30 , and 60 of study.

\section{Results}

Results of isolations are given in table II. By 'predominant', it is implied that the species in question was found in large numbers (about $50 \%$ of colonies on primary culture plates), and was not a normal member of the supposedly harmless respiratory flora. Two such bacteria did not, in our experience, occur simultaneously. Haemophilus influenzae was predominant in 27 of 57 subjects having exacerbations of chronic bronchitis, but in only six of 22 with mucoid sputum and four of 15 postnasal swabs from healthy persons, ie, approximately half of the first and one quarter of the two latter. Streptococcus pneumoniae was predominant in the sputum of eight in exacerbation, of three with mucoid sputum, and of seven, ie, half, of the controls. Escherichia coli and Proteus were predominant only in eight patients who had received ampicillin therapy before admission.

The results of titrations are given in table II, and these also demonstrate an association of $\boldsymbol{H}$. influenzae with exacerbations. Regarding a significant titre as $1: 125$, rising titres to it, reaching a peak at about seven days after admission (figure), were found in all 27 cases in which the organism was predominant in the sputum, and also in eight exacerbations from which it could not be isolated, at that time. Of these last, four had Str. pneumoniae

\begin{tabular}{|c|c|c|c|c|}
\hline Organism & Antigen Content & Culture Medium & $\begin{array}{l}\text { Viable Count } \\
\text { Equivalent to Brown's } \\
\text { Tube No. } 3 \\
\text { (Organisms per } \mathrm{ml} \text { ) }\end{array}$ & $\begin{array}{l}\text { Optimal Test } \\
\text { Concentration } \\
\text { (Organisms per } \mathrm{ml} \text { ) }\end{array}$ \\
\hline Haemophilus influenzae & $\begin{array}{l}\text { Composite antigen containing } \\
\text { rough strains of all six Pittman } \\
\text { capsular types }\end{array}$ & $\begin{array}{l}X+V \text { broth } \\
\text { (May, 1968) }\end{array}$ & $3.4 \times 10^{0}$ & $5 \times 10^{5}$ \\
\hline Streptococcus pneumoniae & $\begin{array}{l}\text { Composite antigen containing } \\
\text { types I, II, \& III }\end{array}$ & $\begin{array}{l}\text { Todd-Hewitt broth } \\
\text { (Oxoid) }\end{array}$ & $2.0 \times 10^{9}$ & $8 \times 10^{5}$ \\
\hline Staphylococcus aureus & $\begin{array}{l}\text { Staph. aureus Oxford } \\
\text { NCTC } 6571\end{array}$ & $\begin{array}{l}\text { Nutrient broth } \\
\text { (Oxoid) }\end{array}$ & $1.3 \times 10^{9}$ & $7.5 \times 10^{5}$ \\
\hline Klebsiella pneumoniae & $\begin{array}{l}\text { K. pneumoniae } \\
\text { NCTC } 9633\end{array}$ & $\begin{array}{l}\text { Nutrient broth } \\
\text { (Oxoid) }\end{array}$ & $1.0 \times 10^{\circ}$ & $5 \times 10^{5}$ \\
\hline Pseudomonas aeruginosa & $\begin{array}{l}\text { Composite antigen containing } \\
\text { Habs serotypes } 3 \text { and } 6\end{array}$ & $\begin{array}{l}\text { Nutrient broth } \\
\text { (Oxoid) }\end{array}$ & $1.2 \times 10^{\circ}$ & $5 \times 10^{5}$ \\
\hline Escherichia coli & $\begin{array}{l}\text { E. coli } \\
\text { NCTC } 8196\end{array}$ & $\begin{array}{l}\text { Nutrient broth } \\
\text { (Oxoid) }\end{array}$ & $1.0 \times 10^{\circ}$ & $5 \times 10^{5}$ \\
\hline Proteus vulgaris & $\begin{array}{l}\text { P. vulgaris } \\
\text { NCTC } 10031\end{array}$ & $\begin{array}{l}\text { Nutrient broth } \\
\text { (Oxoid) }\end{array}$ & $1.0 \times 10^{\circ}$ & $5 \times 10^{5}$ \\
\hline
\end{tabular}

Table I Composition of antigens 


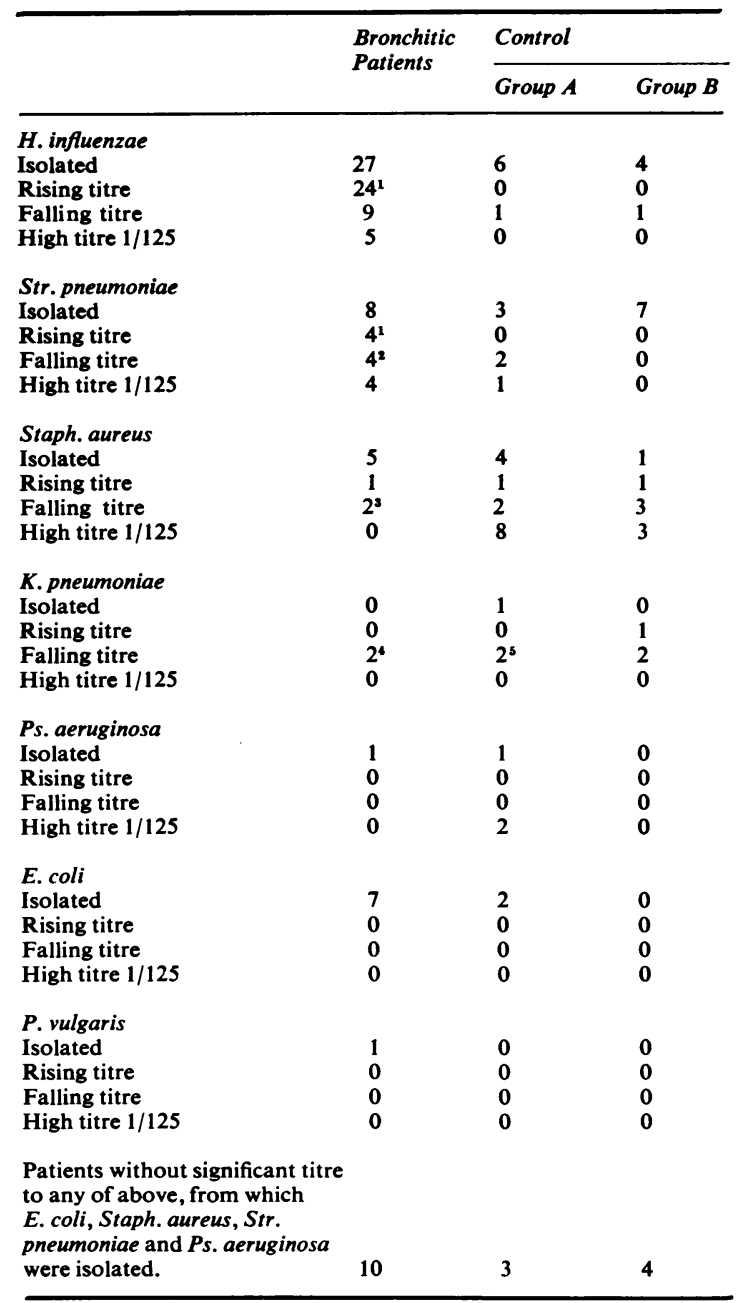

Table II Summary of predominant sputum isolates and agglutinin responses

${ }^{1}$ Two patients had rising titres to both $H$. influenzae and Str. pneumoniae.

${ }^{2}$ Two patients had falling titres to Str. pneumoniae and rising titres to H. influenzae.

'Two patients had falling titres to Staph. aureus and rising titres to H. influenzae.

'One patient had falling $K$. pneumoniae titre with rising $H$. influenzae titre. One patient had falling $K$. pneumoniae titre and $H$. influenzae titre. The $\boldsymbol{H}$. influenzae titre was higher.

${ }^{5}$ Both patients had high titres to Staph. aureus.

as the predominant species in the sputum. Rising titres to $H$. influenzae or Str. pneumoniae were not seen in either control group but both groups had members with falling titres, ie, from an initial level of $1: 125$ or above, to these organisms. In addition, one patient in control group A had a high static titre to Str.pneumoniae.

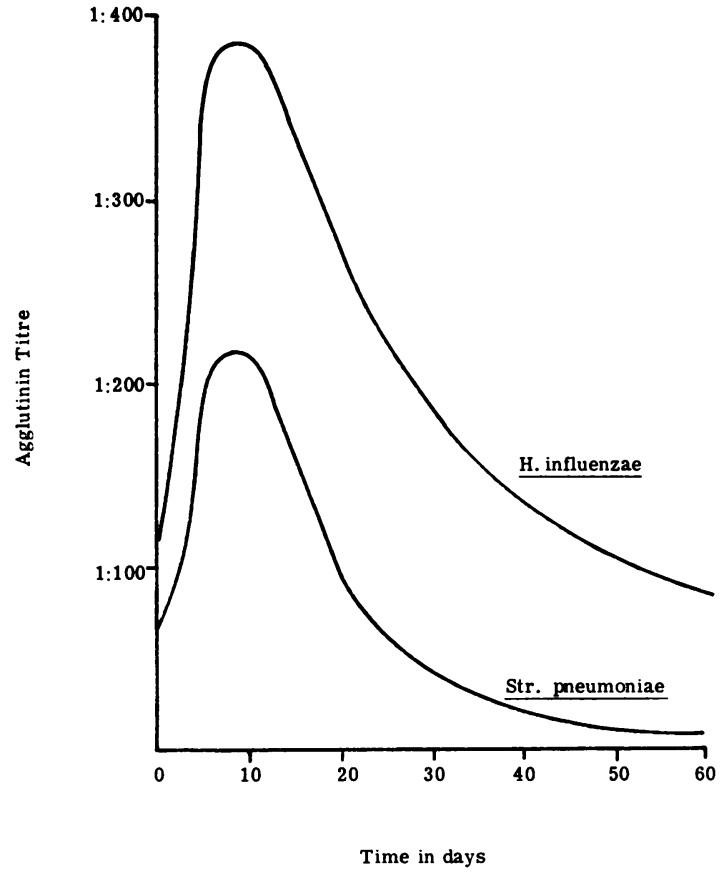

Fig Agglutinin titres against Haemophilus influenzae and $\mathrm{Streptccoccus}$ pneumoniae in 38 cases of acute exacerbation of bronchitis. Interpolative graph, showing average figures, as taken on days 1, 3, 7, 30, and 60 after admission.

\section{Discussion}

It is well established that Haemophilus influenzae may be associated with exacerbations of chronic bronchitis (see Turk and May, 1967; Stuart-Harris, 1968, for references). The results of the present study suggest that the presence of $H$. influenzae in purulent sputum is indicative of infection, but failure to grow the organism cannot exclude its involvement. This has previously been emphasized by May (1968). Although there is a relationship between purulent sputum and infection with $H$. influenzae, little significance can be attached to the presence of this organism in mucoid sputum since it is isolated with the same frequency from the postnasal swabs of healthy persons.

The results of agglutinin titrations support the findings of sputum culture indicating that $H$. influenzae is the major pathogen in exacerbations of chronic bronchitis. Serological investigation indicated that 38 patients were suffering from exacerbations due to this infection. It is interesting that all of the 27 patients from whom $H$. influenzae was isolated were included in this total, but that in six 
patients who had rising titres to it, the organism was not isolated from their sputum.

The role of Str. pneumoniae is less well established and its presence in the sputum of bronchitic patients may be derived from the nasopharynx during expectoration (Brumfitt, Willoughby, and Bromley, 1957; Lees and McNaught, 1959). Str. pneumoniae was the predominant organism in the sputum of eight patients in exacerbation and although it appears that this organism plays a secondary role to $H$. influenzae in chronic bronchitis, the frequency of its isolation from patients with mucoid sputum (three of 22) and from postnasal swabs of healthy persons (seven of 15) makes the distinction between pathogenic and commensal organisms, on the evidence of sputum culture alone, difficult. Serological evidence shows that this organism is not always responsible for an exacerbation even though it is present in the sputum, but failure to isolate it from sputum cannot exclude it as a possible pathogen, and its involvement can only be assessed by serological means. Serological evidence suggests that Str. pneumoniae was probably the pathogen in 12 patients. Two patients had rising titres to both $H$. influenzae and Str. pneumoniae and were obviously suffering an exacerbation froma mixed infection, while two patients with falling titres to Str. pneumoniae had rising titres to $\boldsymbol{H}$. influenzae and were probably suffering sequential infection. It seems, therefore, that Str. pneumoniae was eliciting an active antibody response in 10 patients, five of whom yielded the organism from sputum culture.

The presence of Escherichia coli and Proteus vulgaris in the sputum of bronchitic patients is almost certainly a consequence of antibiotic therapy before admission (May, 1968). In this study all of the eight patients from whom these organisms were isolated had received ampicillin therapy before their admission to hospital. It seems probable that a similar explanation would account for the presence of increased numbers of Staph. aureus and Ps. aeruginosa in bronchitic patients with purulent or mucoid sputum. The lack of involvement of Staph. aureus, $K$. pneumoniae, Ps. aeruginosa, $E$. coli, and $P$. vulgaris in exacerbations of chronic bronchitis as judged by serological means was reported by Burns (1968) and Burns and May (1968).

The significance of agglutinin levels to Staph. aureus is difficult to explain. Staphylococcal infection is experienced by most of the population at some point in their lives, and raised agglutinin levels to Staph. aureus may be present in normal healthy persons (Towers and Gladstone, 1958; Quie and Wannamaker, 1964), although skin lesions and chronic staphylococcal infections may fail to produce a rise in antibody titre (Lack and Towers,
1962; Wilson and Miles, 1964), whereas acute $\frac{\stackrel{0}{\vec{\sigma}}}{3}$ illnesses, such as staphylococcal osteomyelitis, can give a sevenfold or greater increase in titre (Lack, $\stackrel{5}{\rightarrow}$ 1957; Towers and Gladstone, 1958).

In this study 10 patients were without serological evidence of bacterial infection although they appeared to be in acute exacerbation of chronic $\mathbb{\mathbb { D }}$ bronchitis. These may have been caused by virus infection or purely physical disturbance, but a ? second possible explanation is that these patients have developed a degree of immunological tolerance $\overrightarrow{\vec{\omega}}$ towards infection by $H$. influenzae caused by constant exposure to the antigen, especially since $\frac{}{8}$ these four patients had a symptomatic history of $i$ chronic bronchitis of not less than 18 years.

The validity of these serological diagnoses, from is the viewpoint of antibiotic therapy, has been $ช$ evaluated, and shows satisfactory results. This will 옹 be the subject of a separate study.

The authors would like to thank all those patients and healthy volunteers who agreed to participate in this study, and Dr K. A. Bisset for his valuable advice.

One of us (A.C.N.) wishes to thank the Medical Research Council for a research studentship award for the duration of this work.

\section{References}

Brumfitt, W., Willoughby, M. L. N., and Bromley, L. L. (1957). An evaluation of sputum examination in chronic bronchitis. Lancet, 2, 1306-1309.

Burns, M. W. (1968). The significance of various bacteria in chronic bronchial disorders as determined by bacterial antibody detection. Austr. Ann. Med., 17, 289-294.

Burns, M. W., and May, J. R. (1968). Bacterial precipitins in serum of patients with cystic fibrosis. Lancet, 1, 270-272.

Cruickshank, R. (1968). Medical Microbiology, 11 th (revised) ed., pp. 748, 909. Livingstone, Edinburgh.

Faunce, M. (1958). Unpublished data. Cited by May, J. R. (1958). In Recent Trends in Chronic Bronchitis, edited by N. C. Oswald, p. 179. London.

Glynn, A. A. (1959). Antibodies to Haemophilus influenzae in chronic bronchitis. Brit. med. J., 2, 911-914.

Jenne, J. W., MacDonald, F. M., Lapinski, E. M., Bratberg, N. E., and Hall, W. H. (1970). The course of chronic Hemophilus bronchitis treated with marsine doses of penicillin and penicillin combined with streptomycin. Amer. Rev. resp. Dis., 101, 907-922.

Kohn, J. (1965). Antibodies to Haemophilus influenzae. (Letter). Lancet, $1,1337$.

Lack, C. H. (1957). Staphylococcal antibody in osteomyelitis and suppurative arthritis. Proc. roy. Soc. Med., 50, 625-628.

Lack, C. H., and Towers, A. G. (1962). Serological tests for staphylococcal infection. Brit. med. J., 2, 1227-1231.

Lees, A. W., and McNaught, W. (1959). Bacteriology of lower-respiratory-tract secretions, sputum, and upper-respiratory-tract secretions in "normals" and chronic bronchitics. Lancet, 2 , 1112-1115.

May, J. R. (1965). Antibodies to Haemophilus influenzae in the sera of patients with chronic bronchitis. J. Path. Bact., 90, 163-174.

May, J. R. (1968). The Chemotherapy of Chronic Bronchitis and Allied Disorders, p. 108. English Universities Press, London.

Morgan, W. K. C., and Wood, W. H. (1965). Antibody response to Haemophilus influenzae in obstructive airway disease. Lancet, 1,1128-1131.

Murdoch, J. M., Leckie, W. J. H., Downie, J., Swain, R. H. A., and Gould, J. C. (1959). An evaluation of continuous antibiotic therapy in chronic bronchitis. Brit. med. J., 2, 1277-1285. 
Quie, P. G., and Wannamaker, L. W. (1964). Serum antibodies in staphylococcal disease. Pediatrics, 33, 63-70.

Rawlins, G. A. (1953). Liquefaction of sputum for bacteriological examination. Lancet, 2, 538-539.

Ross, C. A. C., McMichael, S., Eadie, M. B., Lees, A. W., Murray, E. A., and Pinkerton, I. (1966). Infective agents and chronic bronchitis. Thorax, 21, 461-464.

Stuart-Harris, C. H. (1968). Chronic bronchitis (Part I), Abstr. Wld Med., 42, 649-669.

Towers, A. C., and Gladstone, G. P. (1958). Two serological tests for staphylococcal infection. Lancet, 2, 1192-1195.

Turk, D. C., and May, J. R. (1967). Haemophilus influenzae: Its Clinical Importance, p. 123. English Universities Press, London.

Wilson, G. S., and Miles, A. A. (1964). Topley and Wilson's Principles of Bacteriology and Immunity, 5th ed., vol. 2, p. 1812. Arnold, London.

Wilson, W. J., Dunn, J. A., and Blair, E. M. M. (1924). Agglutinins for Pfeiffers bacillus found in the sera of patients suffering from influenzae and other diseases. J. Path. Bact., 27, 336-342. 